\title{
Cutaneous Adverse Reactions to Imatinib: A Case Report of a Successful Slow Protocol for Induction of Drug Tolerance
}

\author{
Camilla Di Paolo*, Stefano Minetti, Michela Mineni, Silvia Inverardi, Fabio Lodi Rizzini, Massimo Cinquini and Cinzia Tosoni \\ University of Brescia, Di Brescia Civil Hospital, Brescia, Italy
}

\begin{abstract}
Imatinib mesylate (Gleevec ${ }^{\circledR}$ - Novartis, UK) is a selective tyrosine kinase inhibitor widely used for the treatment of hematologic diseases such as chronic myeloid leukemia (CML). Administration of Imatinib has been related to both cutaneous side effects and hypersensitivity reactions. Since it often is a unique therapeutic option for the treatment of $\mathrm{CML}$, desensitization becomes an option in patients who develop hypersensitivity reactions and do not have equally effective therapeutic options. We hereby propose a possible slow protocol for induction of tolerance, suitable for patients who develop cutaneous delayed reactions.
\end{abstract}

\section{Introduction}

Imatinib mesylate is a tyrosine kinase inhibitor, effective in the treatment of chronic myeloid leukemia (CML) and Hypereosinophilic Syndrome (HES).

As well as other Multikinase Inhibitors (MKI), Imatinib has been related to cutaneous adverse reactions. The majority of these seem to directly depend on its mechanism of action, namely the inhibition of the physiologic function of cutaneous protein kinases, and appear to be dose dependent. Like other traditional chemotherapy agents, MKI cause alopecia, mucositis and xerosis. Cutaneous findings more specifically related to MKI include follicular or papulopustolar exanthemas of the face or chest, dermal atrophy and pruritus. A typical cutaneous side effect in patients treated with MKI is the Hand-Foot Skin Reaction (HFSR) that presents with pain, hyperkeratosis and palmo-plantar blistering, generally occurring in the first 2-4 weeks of treatment. Pathogenesis of HFSR has been related to drug leakage from capillaries damaged by subclinical traumas in areas of frictions, resulting in the histological finding of a superficial perivascular lymphovcytic infiltrate in the dermis, eventually associated to non-leukocytoclastic vasculitis [1].

Other possible cutaneous conditions observed with Imatinib and MKI are caused by immune-mediated hypersensitivity and generally consist in urticaria, angioedema, maculopapular rash up to more severe cases of Acute Generalized Exanthematous Pustolosis, StevensJohnson syndrome, neutrophilic dermatitis, mucositis [2]. Immunemediated cutaneous reactions to MKI are less frequent, generally IgE- or cell-mediated, can occur any time since the beginning of the treatment upon drug sensitization. The main skin reactions associated to Imatinib, according to the presumed pathogenetic mechanism, are listed in Table 1.

So far no allergy testing has been validated to diagnose Imatinib hypersensitivity. For this reason, and since there might be some overlap in the clinical presentation of both dose-dependent and hypersensitivity reactions, a careful clinical evaluation is mandatory in order to assess the type and severity of the reaction and undertake further therapeutic steps, especially with regard to treatment prosecution or discontinuation

The National Cancer Institute has introduced a list of criteria to evaluate the severity of cutaneous adverse reactions, as indicated in Table 2 [3].

In case of adverse reactions, treatment discontinuation and symptomatic therapy are generally indicated. If no alternative therapeutic options are available, the evaluation of the type and severity of the

\begin{tabular}{|c|c|}
\hline Dose-dependent reactions & Hypersensitivity reactions \\
\hline Alopecia & Urticaria \\
\hline Dyschromia & Angioedema \\
\hline Erythema & Anaphylaxis \\
\hline Hand-foot Skin reaction & Maculo-papular rash \\
\hline Pruritus & Stevens-Johnson Syndrome/TEN \\
\hline Seborrheic dermatitis & AGEP \\
\hline Papulopustolar rash & DRESS \\
\hline Exfoliative dermatitis & Exfoliative dermatitis \\
\hline Stomatitis & Stomatitis \\
\hline Subungueal splinter hemorrages & Neutrophilic dermatitis \\
\hline Xerosis & \\
\hline
\end{tabular}

(TEN: Toxic Exanthematous Necrolysis, AGEP: Acute Exanthematous Pustolosis, DRESS: Drug Related Eosinophilia And Systemic Symptoms)

Table 1: Skin reactions associated to Imatinib according to the presumed pathogenetic mechanism.

adverse reaction is crucial. In fact, if the reaction is predictable and dosedependent and it is not extended and severe, it is often possible to avoid treatment discontinuation, combining a topic treatment with emollient or antibiotics or even adding a few weeks-course of systemic steroid and eventually temporarily tapering of the therapeutic dose $[2,4]$.

On the other hand, when the clinical presentation suggests an IgE-mediated hypersensitivity reaction or if the cutaneous lesions are particularly severe, and there are no equally effective therapeutic options available, oral desensitization may be indicated $[5,6]$.

So far, the most quoted desensitization protocol for Imatinib described in literature is a rapid one-day scheme that was applied to 10 patients and was promptly effective in 8 of them [7]. Rapid Desensitization Protocols have been more widely used in the past few

*Corresponding author: Camilla Di Paolo, University of Brescia. SSVD Allergology, Di Brescia Civil Hospital, Civil Hospital p.le 1, Brescia, Italy, Tel: 390303996688 E-mail: camilla.dipaolo@spedalicivili.brescia.it

Received December 16, 2014; Accepted January 09, 2015; Published January 19,2015

Citation: Paolo CD, Minetti S, Mineni M, Inverardi S, Rizzini FL, et al. (2015) Cutaneous Adverse Reactions to Imatinib: A Case Report of a Successful Slow Protocol for Induction of Drug Tolerance. J Allergy Ther 5: 203. doi:10.4172/21556121.1000203

Copyright: ( 2015 Paolo CD, et al. This is an open-access article distributed unde the terms of the Creative Commons Attribution License, which permits unrestricted use, distribution, and reproduction in any medium, provided the original author and source are credited. 
Citation: Paolo CD, Minetti S, Mineni M, Inverardi S, Rizzini FL, et al. (2015) Cutaneous Adverse Reactions to Imatinib: A Case Report of a Successful Slow Protocol for Induction of Drug Tolerance. J Allergy Ther 5: 203. doi:10.4172/2155-6121.1000203

Page 2 of 4

\begin{tabular}{|c|c|c|c|}
\hline & Papulopustular (acneiform) rash & Maculo-papular rash & Hand-foot syndrome \\
\hline Grade 1 & $\begin{array}{l}<10 \% \text { body-surface area, with or without symptoms } \\
\text { of pruritus or tenderness }\end{array}$ & $\begin{array}{l}<10 \% \text { body-surface area, with or without symptoms } \\
\text { (e.g. pruritus, tightness, or burning) }\end{array}$ & $\begin{array}{l}\text { Minimal skin changes (e.g., erythema, edema, or } \\
\text { hyperkeratosis) without pain }\end{array}$ \\
\hline Grade 2 & $\begin{array}{l}10-30 \% \text { body-surface area, with or without symptoms } \\
\text { of pruritus or tenderness; with psychosocial impact; } \\
\text { limiting instrumental activities of daily living }\end{array}$ & $\begin{array}{l}10-30 \% \text { body-surface area with or without } \\
\text { symptoms (e.g. pruritus, tightness, or burning), } \\
\text { limiting instrumental activities of daily living }\end{array}$ & $\begin{array}{l}\text { Skin changes (e.g., peeling, blisters, bleeding, } \\
\text { edema, or hyperkeratosis) with pain; limiting } \\
\text { practical activities }\end{array}$ \\
\hline Grade 3 & $\begin{array}{l}>30 \% \text { body-surface area, with or without symptoms } \\
\text { of pruritus or tenderness; limiting self-care activities } \\
\text { of daily living; associated with local superinfection } \\
\text { with oral antibiotics indicated }\end{array}$ & $\begin{array}{l}>30 \% \text { body-surface area with or without associated } \\
\text { symptoms; limiting self-care activities of daily living }\end{array}$ & $\begin{array}{l}\text { Severe skin changes (e.g., peeling, blisters, } \\
\text { bleeding, edema, or hyperkeratosis) with pain; } \\
\text { limiting self-care activities }\end{array}$ \\
\hline Grade 4 & $\begin{array}{l}\text { Covering any percent of the body-surface area; } \\
\text { with or without symptoms of pruritus or tenderness; } \\
\text { associated with extensive superinfection with IV } \\
\text { antibiotics indicated; life-threatening consequences }\end{array}$ & & \\
\hline Grade 5 & Death & & \\
\hline
\end{tabular}

Table 2: Classification of severity of cutaneous adverse events (as defined by the National Cancer Institute Common Toxicity Criteria, version 4.03).

years in the management of chemotherapy agents hypersensitivity reactions, as more and more reports are available on their safety and effectiveness. However, depending on the clinical presentation, they might not be suitable for all patients. Those who present with delayed, non IgE-mediated clinical manifestations might benefit from slow desensitization. This solution results generally safe and seems to enhance metabolic adaptation, eventually resulting in a more rapid and efficient clearance of reactive drug metabolites that might stimulate the immune response underlying allergic reactions [8].

We describe the case of a 72 year-old man who was diagnosed chronic phase CML and prescribed Imatinib $400 \mathrm{mg}$ daily. After developing a delayed cutaneous reaction, he underwent an initial rapid desensitization attempt that caused cutaneous symptoms relapses. Finally, following a slow 10-days desensitization scheme, the patient was able to tolerate Imatinib.

\section{Case Report}

A 72 year-old man with $\mathrm{Ph}+\mathrm{CML}$ was treated with Imatinib 400 mg daily. He had normal renal function and no other co-morbidities requiring chronic treatment. Six weeks after starting Imatinib, he developed a diffuse erythematous pruritic rash. Hence, Imatinib therapy was discontinued and the patient was prescribed a five days course of prednisone. After complete resolution of the skin lesions was achieved, the treatment with Imatinib was restarted but the rash relapsed in a few days. Following a new course of prednisone, the last attempt to reintroduce Imatinib was performed but due to a further recurrence of the rash, the drug was finally discontinued.

A skin biopsy was performed with histological findings suggesting a chronic, superficial eosinophilic dermatitis, confirming the suspect of a cutaneous adverse drug reaction.

Given the high response rate expected with Imatinib and the absence of associated significant clinical conditions, the patient was referred to our Center for desensitization.

Before desensitization, the patient gave informed consent and underwent skin tests. Since no validated diagnostic allergy skin tests are available with Imatinib, a $100 \mathrm{mg}$ capsule was diluted in sterile water and skin prick tests with $0.1 \mathrm{mg} / \mathrm{ml}$ and whole drug were performed as well as intradermal tests with $0.0001 \mathrm{mg} / \mathrm{ml}, 0.001 \mathrm{mg} / \mathrm{ml}, 0.01 \mathrm{mg} / \mathrm{ml}$ and $0.1 \mathrm{mg} / \mathrm{ml}$. Patch test with $0.1 \mathrm{mg} / \mathrm{ml}$ in $5 \%$ petrolatum was also performed. All tests resulted negative.

Desensitization was initially performed according to the protocol published by Nelson et al. modified in order to reach a target dose of $377 \mathrm{mg}$ in 2 days, as shown in table 3. Stock suspensions of Imatinib were prepared dissolving the content of a $100 \mathrm{mg}$ capsule in sterile water at the following concentrations: $10 \mathrm{ng} / \mathrm{ml}, 100 \mathrm{ng} / \mathrm{ml}, 1 \mathrm{mcg} / \mathrm{ml}$, $10 \mathrm{mcg} / \mathrm{ml}, 100 \mathrm{mcg} / \mathrm{ml}, 1 \mathrm{mg} / \mathrm{ml}$ and $10 \mathrm{mg} / \mathrm{ml}$.

On day 1 the patient was administered a cumulative dose of $0.77 \mathrm{mg}$ of Imatinib with increasing doses given every 20 minutes. The following day, the cumulative dose of $377 \mathrm{mg}$ of Imatinib was reached in 5 steps

The patient well tolerated the entire desensitization protocol and no adverse reactions were observed. However, 10 days later, he experienced a new flare of cutaneous rash that required prednisone treatment. After skin lesions healed the patient underwent the same 2 days- desensitization protocol again (Table 3).

The second desensitization attempt was well tolerated but 4 days later a cutaneous rash relapsed on the limbs. When the skin lesions healed, desensitization was once again reattempted but the protocol was further modified, in order to allow a more gradual increase of the doses, starting from a higher concentration and reaching the target

\begin{tabular}{|c|c|c|c|}
\hline & Concentration & Volume, ml & Daily Cumulative Dose, (mg) \\
\hline \multicolumn{4}{|l|}{ Day 1} \\
\hline & \multirow{3}{*}{$10 \mathrm{ng} / \mathrm{ml}$} & 1 & 0.00001 \\
\hline & & 2 & 0.00003 \\
\hline & & 4 & 0.00007 \\
\hline & \multirow{3}{*}{$100 \mathrm{ng} / \mathrm{ml}$} & 1 & 0.00017 \\
\hline & & 2 & 0.00037 \\
\hline & & 4 & 0.00077 \\
\hline & \multirow{3}{*}{$1 \mathrm{mcg} / \mathrm{ml}$} & 1 & 0.00177 \\
\hline & & 2 & 0.00377 \\
\hline & & 4 & 0.00777 \\
\hline & \multirow{3}{*}{$10 \mathrm{mcg} / \mathrm{ml}$} & 1 & 0.01777 \\
\hline & & 2 & 0.03777 \\
\hline & & 4 & 0.07777 \\
\hline & \multirow{3}{*}{$100 \mathrm{mcg} / \mathrm{ml}$} & 1 & 0.17777 \\
\hline & & 2 & 0.37777 \\
\hline & & 4 & 0.77777 \\
\hline \multicolumn{4}{|l|}{ Day 2} \\
\hline & \multirow{3}{*}{$1 \mathrm{mg} / \mathrm{ml}$} & 1 & 1 \\
\hline & & 2 & 3 \\
\hline & & 6 & 10 \\
\hline & \multirow{3}{*}{$10 \mathrm{mg} / \mathrm{ml}$} & 1 & 20 \\
\hline & & 2 & 40 \\
\hline & & 60 & 100 \\
\hline & $100 \mathrm{mg}$ tab & 1 & 200 \\
\hline & $2 \times 100 \mathrm{mg}$ tab & 2 & 400 \\
\hline
\end{tabular}

Table 3: Imatinib oral desensitization protocol. 
Citation: Paolo CD, Minetti S, Mineni M, Inverardi S, Rizzini FL, et al. (2015) Cutaneous Adverse Reactions to Imatinib: A Case Report of a Successful Slow Protocol for Induction of Drug Tolerance. J Allergy Ther 5: 203. doi:10.4172/2155-6121.1000203

\begin{tabular}{|c|c|c|c|c|}
\hline \#of days & Concentration & Volume $(\mathrm{ml})^{*}$ & Dose (mg) & $\begin{array}{l}\text { Daily Cumulative } \\
\text { Dose (mg) }\end{array}$ \\
\hline 1 & $1 \mathrm{mg} / \mathrm{ml}$ & $\begin{array}{l}1 \\
2 \\
4\end{array}$ & $\begin{array}{l}1 \\
2 \\
4\end{array}$ & 7 \\
\hline 3 & $10 \mathrm{mg} / \mathrm{ml}$ & $\begin{array}{l}1 \\
2 \\
4\end{array}$ & $\begin{array}{l}10 \\
20 \\
40\end{array}$ & 70 \\
\hline 3 & $100 \mathrm{mg}$ tab & $1 \mathrm{tab}$ & 100 & 100 \\
\hline 1 & $\begin{array}{c}100 \mathrm{mg} \mathrm{tab} \\
1 \mathrm{mg} / \mathrm{ml}\end{array}$ & $\begin{array}{c}1 \text { tab } \\
1 \\
2 \\
4\end{array}$ & $\begin{array}{c}100 \\
1 \\
2 \\
4\end{array}$ & 107 \\
\hline 3 & $\begin{array}{c}100 \mathrm{mg} \mathrm{tab} \\
10 \mathrm{mg} / \mathrm{ml}\end{array}$ & $\begin{array}{c}1 \text { tab } \\
1 \\
2 \\
4\end{array}$ & $\begin{array}{c}100 \\
10 \\
20 \\
40\end{array}$ & 170 \\
\hline 3 & $100 \mathrm{mg}$ tab & 2 tab & 200 & 200 \\
\hline 1 & $\begin{array}{c}100 \mathrm{mg} \mathrm{tab} \\
10 \mathrm{mg} / \mathrm{ml}\end{array}$ & $\begin{array}{c}2 \text { tab } \\
1 \\
2 \\
4\end{array}$ & $\begin{array}{c}200 \\
10 \\
20 \\
40\end{array}$ & 270 \\
\hline 6 & $100 \mathrm{mg}$ tab & 3 tab & 300 & 300 \\
\hline 1 & $\begin{array}{c}100 \mathrm{mg} \mathrm{tab} \\
10 \mathrm{mg} / \mathrm{ml}\end{array}$ & $\begin{array}{c}3 \text { tab } \\
1 \\
2 \\
4\end{array}$ & $\begin{array}{c}300 \\
10 \\
20 \\
40\end{array}$ & 370 \\
\hline 1 & $100 \mathrm{mg}$ tab & $4 \mathrm{tab}$ & 400 & 400 \\
\hline
\end{tabular}

*Increasing doses on the same day are administered every 20 minutes.

Table 4: Modified Imatinib oral desensitization protocol.

dose in 21 days, as shown in Table 4.

According to this modified protocol, the initial induction phase was carried out in 13 days, with no recording of adverse events. Once the $200 \mathrm{mg}$ dose was reached and tolerated, the further dosage increases were administered at an even slower rate, achieving the therapeutic dose of $400 \mathrm{mg}$ within 9 more days. From then on, the patient was able to continue daily Imatinib. He has now been on treatment for 18 months without further adverse events.

\section{Discussion}

Skin rashes are a well-recognized side effect of Imatinib treatment. In most cases, the lesions are mild, self-limiting, and easily managed with anti-histamines or topical steroids, whereas a short course of oral steroids can be used to treat more severe cases [9]. Grade 3 or 4 skin rashes may occur in $3.8 \%$ of patients. In some patients, severe rashes can develop with desquamative components, including a report of StevenJohnson syndrome $[10,11]$. In such cases, immediate discontinuation of therapy and systemic steroids are indicated. Severe skin lesions resistant to supportive measures have been the most frequent cause for permanent discontinuation of Imatinib therapy, though occurring in less than $1 \%$ of patients [9]. Several studies have reported a dose related skin toxicity of Imatinib, indicating a pharmacological effect of Imatinib that ranges from xerosis, cutaneous rashes to the more specific HFSR.

We presented the case of a patient with CML who developed an eosinophilic dermatitis after 6 weeks of treatment with Imatinib. It is not clear whether such clinical presentation is related to the pharmacological effect of Imatinib, to a delayed type hypersensitivity or both $[12,13]$.

Standard management of drug induced skin rashes usually includes discontinuation of the suspected drug and avoidance of further exposure to the culprit drug in the future. However, given the effectiveness of Imatinib, most clinicians try to continue or reinitiate treatment with Imatinib. To overcome severe skin reactions, several

methods such as temporary discontinuation, weekly administration, lower daily dose with or without a short course of an oral corticosteroid and desensitization and or induction of tolerance through gradual dosage increases have been reported $[2,4,11]$.

Induction of drug tolerance consists in the progressive administration of increasing doses of a culprit drug in order to render immune effector cells less reactive. This eventually occurs through immunologic, both IgE mediated and/or cell-mediated mechanisms or even non immunologic unknown mechanisms. The resulting state is temporary, and its maintenance requires continuous administration of the offending drug.

Drug desensitization procedures vary with individual drugs; they have been mainly studied for agents that induce IgE-mediated reactions (eg. Penicillins) and in some cases of anaphylactoid (non-IgE-mediated anaphylaxis) reactions (eg. NSAIDs). In this case the desensitization is generally performed within hours, with a starting dose is in the microgram range [14].

A slow desensitization protocol appears suitable in order to reestablish drug tolerance when the clinical presentation of the patient suggests a delayed, cell-mediated pathogenesis, as in the case of cutaneous rashes. In the literature, slow protocols are well established for trimetoprim/sulfamethoxazole, allopurinol and some antiretroviral and anti-mycobacterial agents $[8,15,16]$. They have proved safe and effective and eventually suitable for tolerance induction even in non Ig-E mediated adverse reactions. Indeed, slow desensitization protocol seems to enhance metabolic adaptation, with a subsequent more rapid and efficient clearance of reactive drug metabolites that might play a role both in allergic and non-allergic adverse reactions [8].

Given the increasing number of reports of non-immediate cutaneous reactions to multi-kinase inhibitors, and more specifically to Imatinib [17], a slow drug tolerance induction protocol could be a first line treatment option in patients who develop such adverse reactions as it might reduce the risk of cutaneous symptoms relapses, whose severity is unpredictable, reduces the need of symptomatic treatments, including corticosteroid therapy that can lead to serious side effects in the long term.

A suitable protocol for induction of tolerance in patients with cutaneous reactions is presented in Table 5 .

\begin{tabular}{|c|c|c|c|}
\hline \#of days & Concentration & Volume (ml) & Cumulative Daily Dose (mg) \\
\hline & $10 \mathrm{ng} / \mathrm{ml}$ & $1,2,4$ & \\
1 & $100 \mathrm{ng} / \mathrm{ml}$ & $1,2,4$ & 0.077 \\
& $1 \mathrm{mcg} / \mathrm{ml}$ & $1,2,4$ & \\
\hline 1 & $10 \mathrm{mcg} / \mathrm{ml}$ & $1,2,4$ & 7 \\
\hline 3 & $100 \mathrm{mcg} / \mathrm{ml}$ & $1,2,4$ & 70 \\
\hline 3 & $1 \mathrm{mg} / \mathrm{ml}$ & $1,2,4$ & 100 \\
\hline & $10 \mathrm{mg} / \mathrm{ml}$ & $1,2,4$ & 107 \\
\hline 3 & $100 \mathrm{mg} \mathrm{tab}$ & 1 & 170 \\
\hline 3 & $100 \mathrm{mg} \mathrm{tab}$ & 1 & 200 \\
\hline 1 & $100 \mathrm{mg} / \mathrm{ml}$ & $1,2,4$ & 270 \\
\hline 6 & $10 \mathrm{mg} / \mathrm{ml}$ & 1 & \\
\hline 1 & $100 \mathrm{mg} \mathrm{tab}$ & 2 & 300 \\
\hline 1 & $100 \mathrm{mg} \mathrm{tab}$ & 2 & 370 \\
\hline & $100 \mathrm{mg} / \mathrm{ml}$ & $1,2,4$ & 400 \\
\hline
\end{tabular}

"Increasing doses on the same day are administered every 20 minutes.

Table 5: A comprehensive Imatinib oral slow desensitization protocol. 
Citation: Paolo CD, Minetti S, Mineni M, Inverardi S, Rizzini FL, et al. (2015) Cutaneous Adverse Reactions to Imatinib: A Case Report of a Successful Slow Protocol for Induction of Drug Tolerance. J Allergy Ther 5: 203. doi:10.4172/2155-6121.1000203

\section{References}

1. Giles FJ (2009) The toxicities of modern targeted therapies -learning from the price of progress. Target Oncol 4: 65-66

2. Rule SA, O'Brien SG, Crossman LC (2002) Managing cutaneous reactions to imatinib therapy. Blood 100: 3434-3435

3. US Department of Health and Human Services (2010) Common Terminology Criteria for Adverse Events (CTCAE) 4

4. Tanvetayanon $T$, Nand $S$ (2003) Overcoming recurrent cutanous reactions from imatinib using once-weekly dosing. Ann Pharmacother 37: 1818-1820

5. Wendel GD, Stark BJ, Jamison RB, Molina RD, Sullivan TJ (1985) Penicillin allergy and desensitization in serious infections during pregnancy. $\mathrm{N}$ Engl J Med 312: 1229-1232.

6. Smith RM, Iwamoto GK, Richerson HB, Flaherty JP (1987) Trimetophrimsulfamethoxazole desensitizazion in acquired immunodeficiency syndrome. Ann Intern Med 106: 335

7. Nelson RP, Cornetta K, Ward KE, Ramanuja S, Fausel C, et al. (2006) Desensitization to imatinib in patients with leukemia. Ann Allergy Asthma Immunol 97: 216-222

8. Fam AG (2001) Efficacy and safety of desensitization to allopurinol following cutaneous reactions. Arthritis and Rheumatism 44: 231-238

9. Deininger MV, O'Brein SG, Ford JM, Durker BJ (2003) Practical Management of patients with chronic myeloid leukemia receiving imatinib. J Clin Oncol 21 1637-1647
10. Scott LC, White JD, Reid R, Cowie F (2005) Management of Skin Toxicity Related to the Use of Imatinib Mesylate (STI571, Glivec Trademark) for Advanced stage Gastrointestinal Stromal Tumors. Sarcoma 9: 157-160

11. Hsiao LT, Chung HM, Lin JT, Chiou TJ, Liu JH et al. (2002) Stevens Johnson syndrome after treatment with STI571: a case report. Br J Hematol 117: 620622

12. Valeyrie L, Bastuji-Garin S, Revuz J, Bachot N, Wechsler J, et al. (2003) Adverse cutaneous reactions to imatinib (STI571) in Philadelphia chromosome-positive leukemias: a prospective study of 54 patients. J Am Acad Dermatol 48: 201-206

13. Brouard M, Saurat JH (2001) cutaneous reactions to STI571. N Engl J Med 345: 618-619

14. Castells M (2006) Desensitization for drug allergy. Curr Opin Allergy Clin Immunol 6: 476-481

15. Absar N, Daneshvar H, Beall G (1994) Desensitization to trimethoprim/ sulfamethoxazole in HIV-infected patients. J Allergy Clin Immunol 93: 10011005

16. Matz J, Borish LC, Routes JM, Rosenwasser LJ (1994) Oral desensitization to rifampin and ethambutol in mycobacterial disease. Am J Respir Crit Care Med. 149: 815-817.

17. Park MA, Volcheck GW, Guarderas JC (2004) Successful progressive challenge after a cutaneous reaction to imatinib mesylate (Gleevec): a case report and review of the literature. Allergy Asthma Proc. 25: 345-347 